\title{
A comparison of clinical paediatric guidelines for hypotension with population-based lower centiles: a systematic review
}

Nienke N. Hagedoorn, Joany M. Zachariasse and Henriette A. Moll*

\begin{abstract}
Background: Different definitions exist for hypotension in children. In this study, we aim to identify evidence-based reference values for low blood pressure and to compare these with existing definitions for systolic hypotension.

Methods: We searched online databases until February 2019 (including MEDLINE, EMBASE, Web of Science) using a comprehensive search strategy to identify studies that defined age-related centiles (first to fifth centile) for noninvasive systolic blood pressure in healthy children $<18$ years. Existing cut-offs for hypotension were identified in international guidelines and textbooks. The age-related centiles and clinical cut-offs were compared and visualized using step charts.

Results: Fourteen studies with population-based centiles were selected, of which 2 addressed children $<1$ year. Values for the fifth centile differed 8 to $17 \mathrm{mmHg}$ for age. We identified 13 clinical cut-offs of which only 5 reported accurate references. Age-related cut-offs for hypotension showed large variability (ranging from 15 to $30 \mathrm{mmHg}$ ). The clinical cut-offs varied in agreement with the low centiles. The definition from Paediatric Advanced Life Support agreed well for children $<12$ years but was below the fifth centiles for children $>12$ years. For children $>12$ years, the definition of Parshuram's early warning score agreed well, but the Advanced Paediatric Life Support definition was above the fifth centiles.

Conclusions: The different clinical guidelines for low blood pressure show large variability and low to moderate agreement with population-based lower centiles. For children $<12$ years, the Paediatric Advanced Life Support definition fits best but it underestimates hypotension in older children. For children $>12$ years, the Advanced Paediatric Life Support overestimates hypotension but Parshuram's cut-off for hypotension in the early warning score agrees well. Future studies should focus on developing reference values for hypotension for acutely ill children.
\end{abstract}

Keywords: Vital signs, Hypotension, Percentiles, Reference values

\footnotetext{
* Correspondence: h.a.moll@erasmusmc.nl

Department of Paediatrics, Room Sp 1540, Erasmus MC-Sophia Children's

Hospital, University Medical Centre Rotterdam, PO Box 2060, 3000 CB

Rotterdam, The Netherlands
}

(C) The Author(s). 2019 Open Access This article is distributed under the terms of the Creative Commons Attribution 4.0 International License (http://creativecommons.org/licenses/by/4.0/), which permits unrestricted use, distribution, and reproduction in any medium, provided you give appropriate credit to the original author(s) and the source, provide a link to the Creative Commons license, and indicate if changes were made. The Creative Commons Public Domain Dedication waiver (http://creativecommons.org/publicdomain/zero/1.0/) applies to the data made available in this article, unless otherwise stated. 


\section{Introduction}

Vital signs are important in the recognition of acutely ill children. One parameter associated with serious illness is hypotension [1-3]. Because normal blood pressure values vary with age, accurate age-related reference values are needed to correctly identify hypotension in children and guide interventions.

Blood pressure can be measured by invasive, oscillometric and auscultatory methods. In addition, various outcome measures for blood pressure exist such as mean arterial pressure, and diastolic and systolic blood pressure. Paediatric guidelines propose different definitions of hypotension and in general use cut-off values of systolic blood pressure [4-6]. Although not based on evidence, several guidelines use the fifth percentile of systolic blood pressure in healthy children as cut-off for hypotension [4, 7, 8]. Moreover, it is unclear how well these guidelines discriminate between normal and low blood pressure. To date, no study has summarized the available evidence on reference values of low systolic blood pressure in children.

This study aims to identify population-based reference values for non-invasive low blood pressure in healthy children and to compare these with cut-offs for hypotension defined by existing paediatric guidelines.

\section{Methods}

Search strategy and selection of population-based studies We systematically searched databases including MEDLINE, EMBASE and other databases (1950 to 14 February 2019) to identify primary studies that defined lower centiles for non-invasive systolic blood pressure measurement in healthy children (Additional file 1: detailed search strategy). Studies that were included were published in English, recorded blood pressure and defined age-related centiles for systolic blood pressure (first to fifth centile) on a minimum of 100 children aged $<18$ years. Studies were excluded if populations involved children with underlying diseases, or studies reporting on premature neonates, measurements during anaesthesia, exercise or orthostasis. We excluded populations from low- and middle-income countries since factors influencing blood pressure levels, such as body composition and nutrition, are different compared to high-income countries [9]. We excluded abstracts, reviews and commentaries, and studies reporting on lower centiles solely derived from mathematical analysis. One researcher $(\mathrm{NH})$ conducted the first selection, and two researchers $(\mathrm{NH}, \mathrm{JZ})$ independently conducted the second and third selection. Disagreements were discussed and agreed upon consensus or discussed with a third researcher (HM) for majority decision.

\section{Data extraction and analysis}

For the selected studies, data were extracted by one researcher $(\mathrm{NH})$ and included country, population, setting, sample size, age range, blood pressure measurement method and age-specific centiles (P1-P5). We included the centiles for non-overweight children and for the median height if blood pressure centile values were reported for different height categories. The age-specific fifth centiles were summarized using weighted medians and interquartile ranges for age categories which involved three or more studies. If sample sizes were only given for age ranges $>1$ year, we estimated the sample size per age group by dividing the total sample size by the number of years.

\section{Quality assessment}

No specific tool exists for quality assessment of observational studies [10]. The Quality Assessment of Diagnostic Accuracy Studies-2 checklist was the most appropriate to use for these observational studies [11]. This checklist covers risk of bias and applicability judgements on four domains: patient selection, index test, reference standard and flow and timing. For each question, studies were classified as high, low or unclear. Disagreements were agreed upon consensus.

\section{Cut-off values for hypotension from clinical guidelines}

We selected a sample of clinical cut-offs for hypotension by consulting experts, well-known textbooks and resuscitation, emergency care and sepsis guidelines. Clinical cut-offs included recommended target values for hypotension defined by systolic blood pressure. For each clinical cut-off, we determined the presence of a literature reference and whether this reference agreed with the cut-off values. To compare clinical cut-offs with the population-based centiles identified in the literature, we plotted the age-specific fifth centile values in a step chart separate for boys and girls. Data analyses were performed in SPSS version 25.0 and $R$ version 3.4.

\section{Results \\ Population-based studies}

Our systematic search identified 7625 studies. After the study selection process, we included 14 studies in the final selection that defined lower centiles for noninvasive systolic blood pressure measurement in healthy children (Fig. 1). The median sample size was 5362 (IQR 1760-11,940). Seven out of 14 studies used an automatic oscillometric device for blood pressure measurement. Two studies included children aged $<1$ year (Table 1 ). Studies included populations from Europe $(n=8)$, North America $(n=3)$, Australia $(n=2)$ and Asia $(n=1)$. Four studies excluded overweight patients. For development of the centiles, 11 studies used the average of multiple 


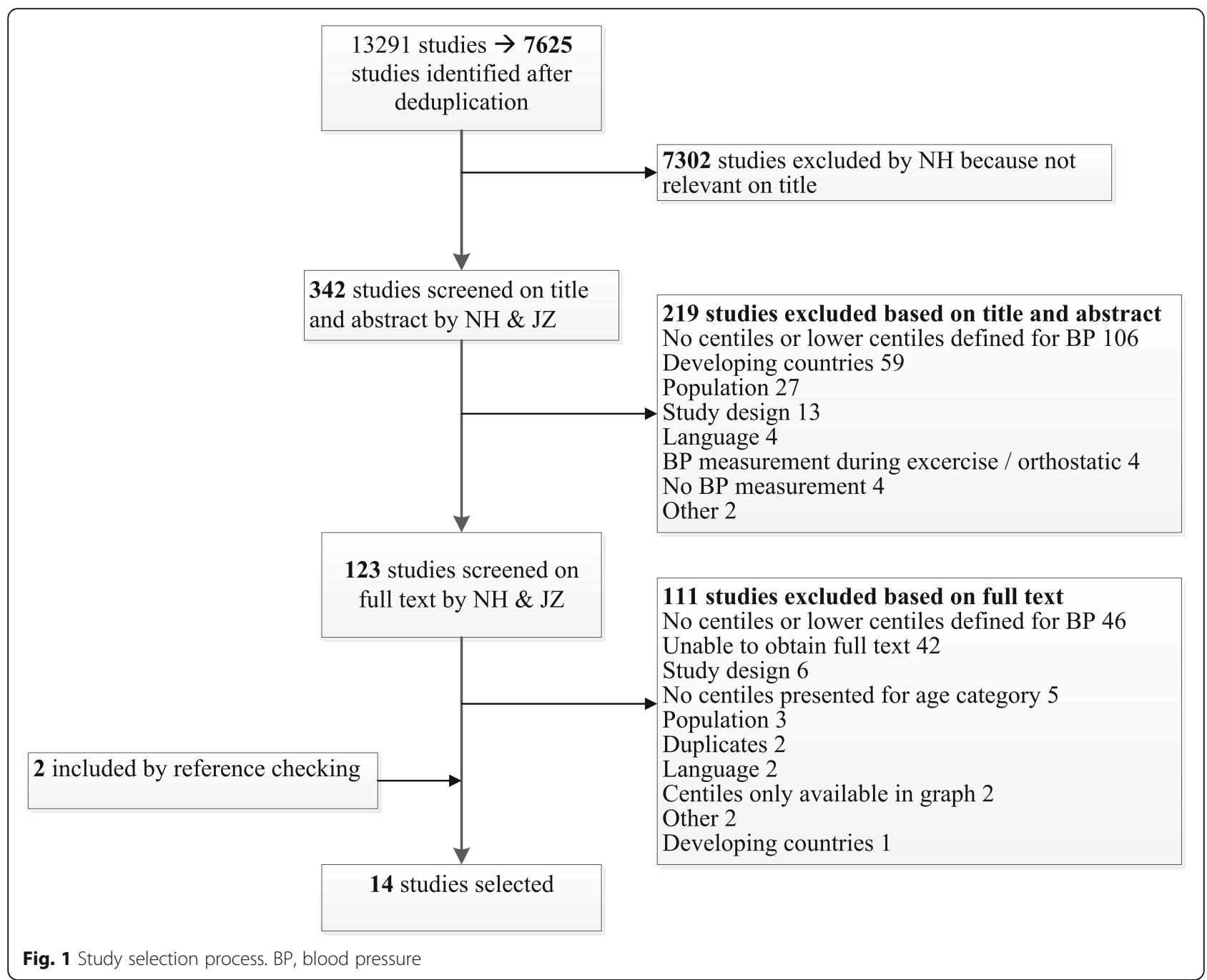

blood pressure measurements and 3 studies used only the first measurement. Blood pressure centiles were stratified by gender $(n=12)$, height $(n=4)$, ethnicity $(n=1)$ and overweight vs non-overweight $(n=2)$. Studies most frequently reported the fifth centile $(n=13)$, in which the third centile $(n=2)$ and first centile $(n=3)$ were also reported separately. One study only reported the first and third centiles. The fifth centiles of the populationbased studies showed variation ranging across the age groups from 7 to $17 \mathrm{mmHg}$ for boys (Fig. 2) and 7 to 22 $\mathrm{mmHg}$ for girls (Additional file 2). Median values and interquartile ranges of the lower fifth centiles are provided in Additional files 3 and 4.

Quality of the population studies was generally good. No concerns regarding applicability were found in 12 out of 14 studies. Six studies had high risk of bias in the patient flow and timing domain, due to poor reporting of how missing data were handled (Table 2, Fig. 3).

\section{Cut-off values for hypotension from clinical guidelines}

We identified 13 clinical cut-offs for hypotension of which 8 referred to a literature reference (Additional file 5). Five cutoffs provided an accurate literature reference [7, 27-30], of which four out of five referred to the fifth centile of healthy children. In two textbooks, the values of the literature reference did not agree with the provided cut-offs [31, 32]. One literature reference could not be obtained [33]. Age-specific cut-off values for hypotension showed large differences, ranging from 15 to $30 \mathrm{mmHg}$ (Fig. 2, Additional file 5).

\section{Comparison of population-based studies with cut-off values for hypotension from clinical guidelines}

The clinical hypotension cut-offs showed poor to moderate agreement with the lower centiles derived from population-based studies (Fig. 2). The frequently used hypotension cut-off from Advanced Paediatric Life Support (APLS) [6] showed moderate agreement for 


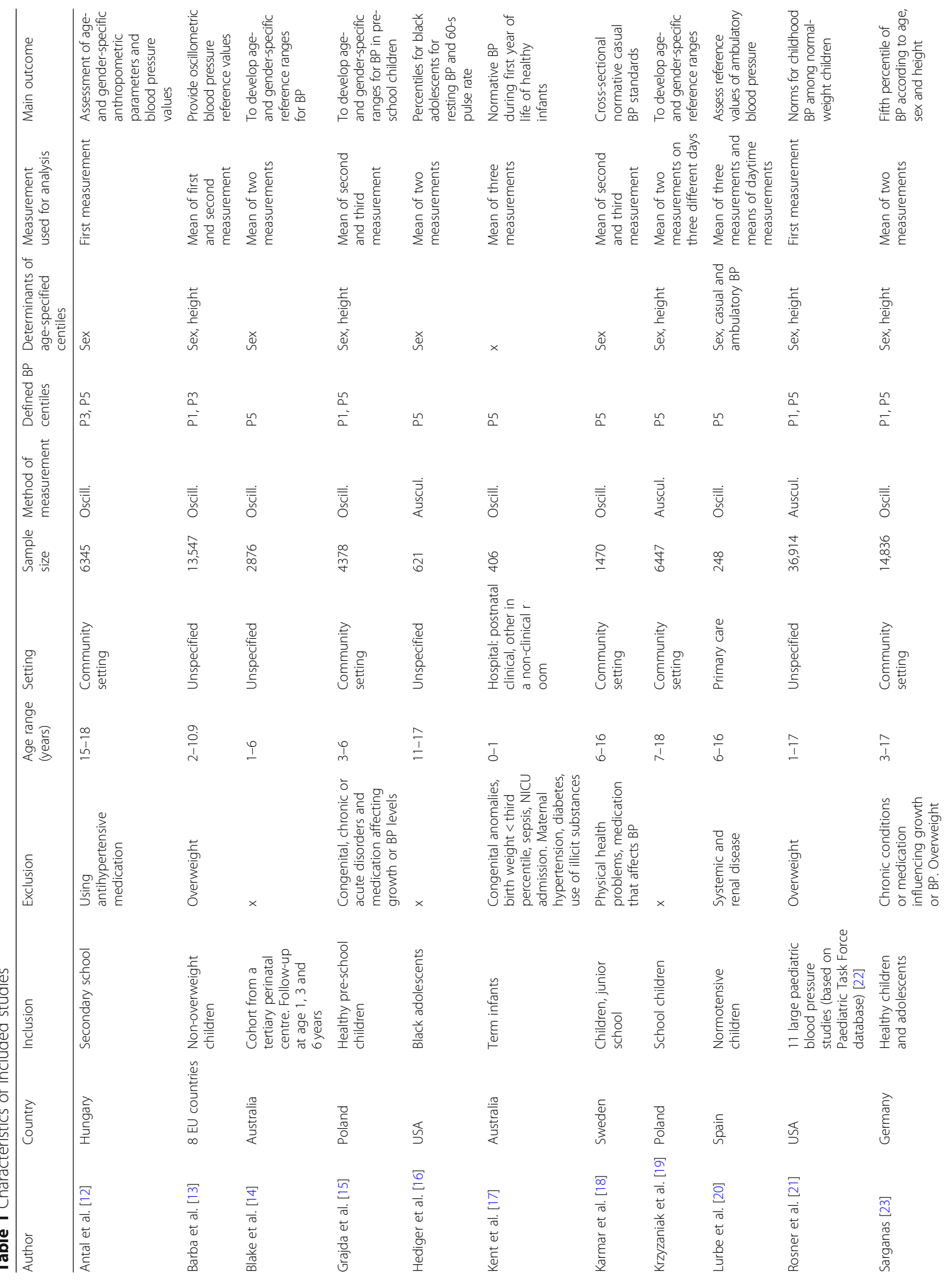


Hagedoorn et al. Critical Care $\quad$ (2019) 23:380

Page 5 of 10

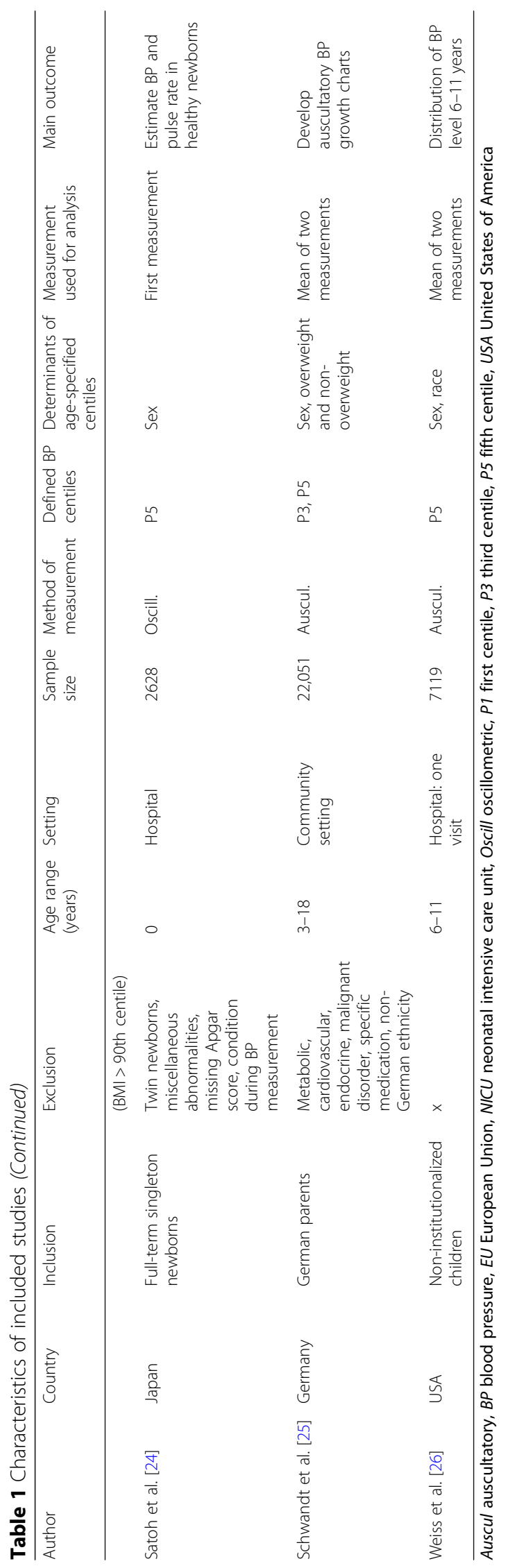




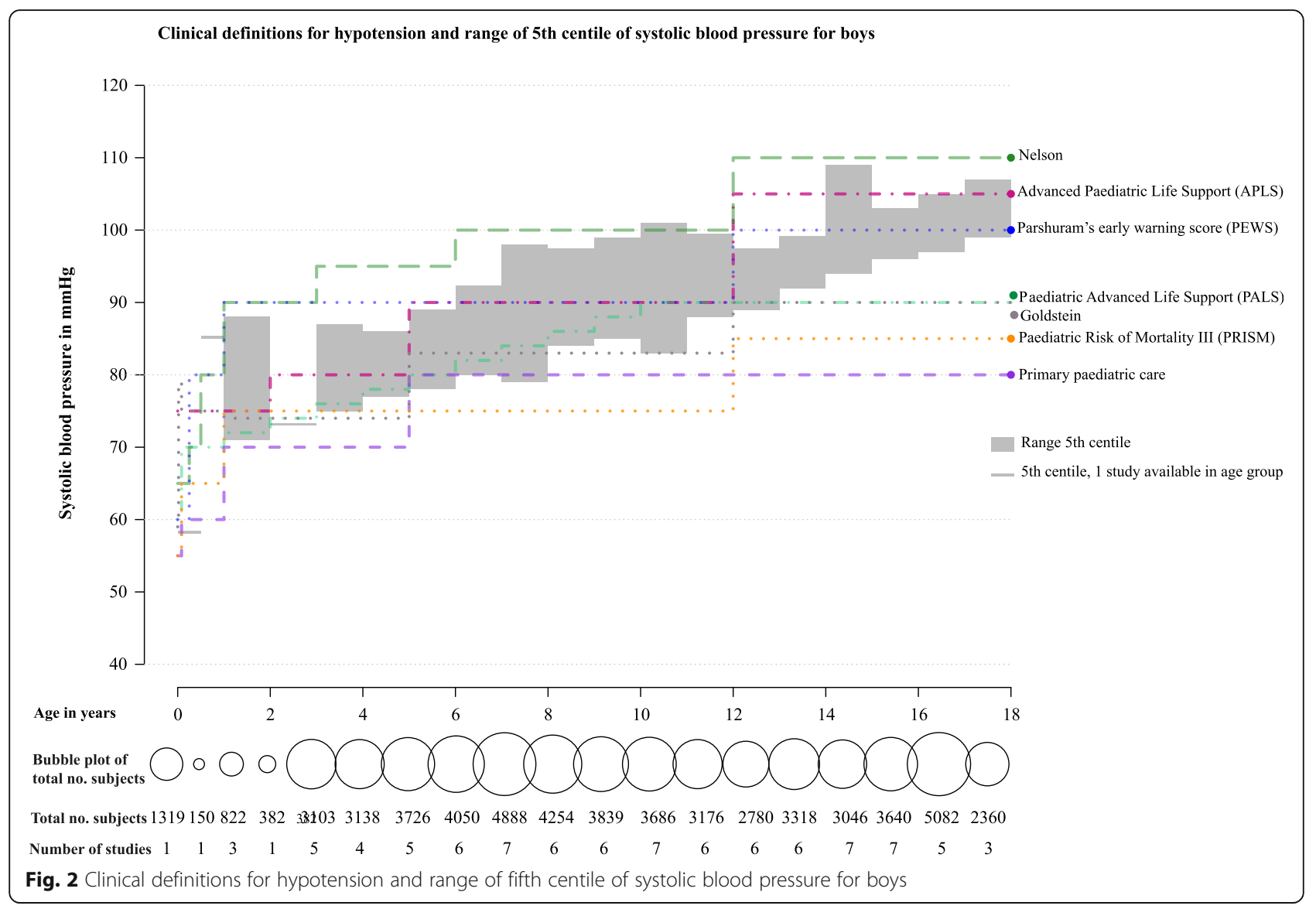

Table 2 Quality assessment of the studies

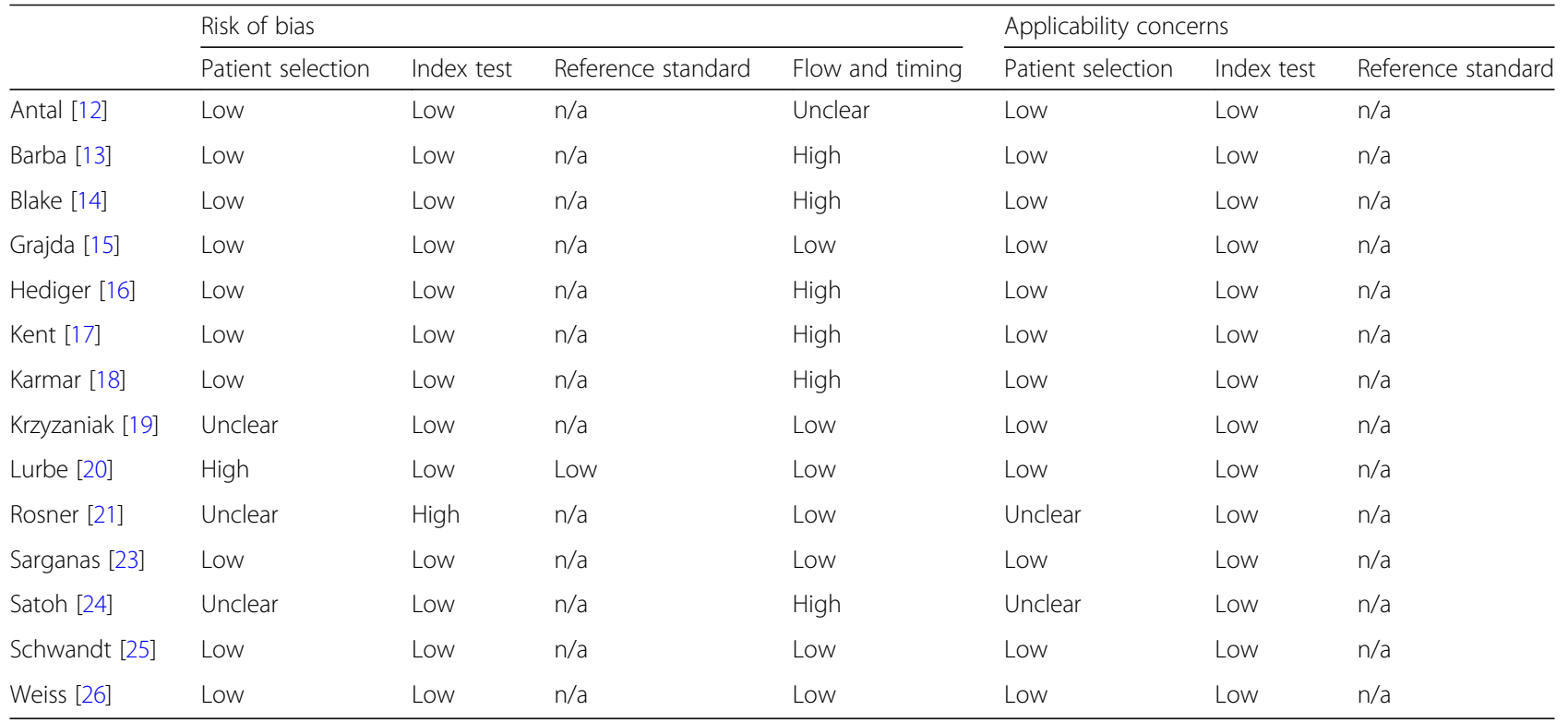


Figure 3 Quality assessment of the studies
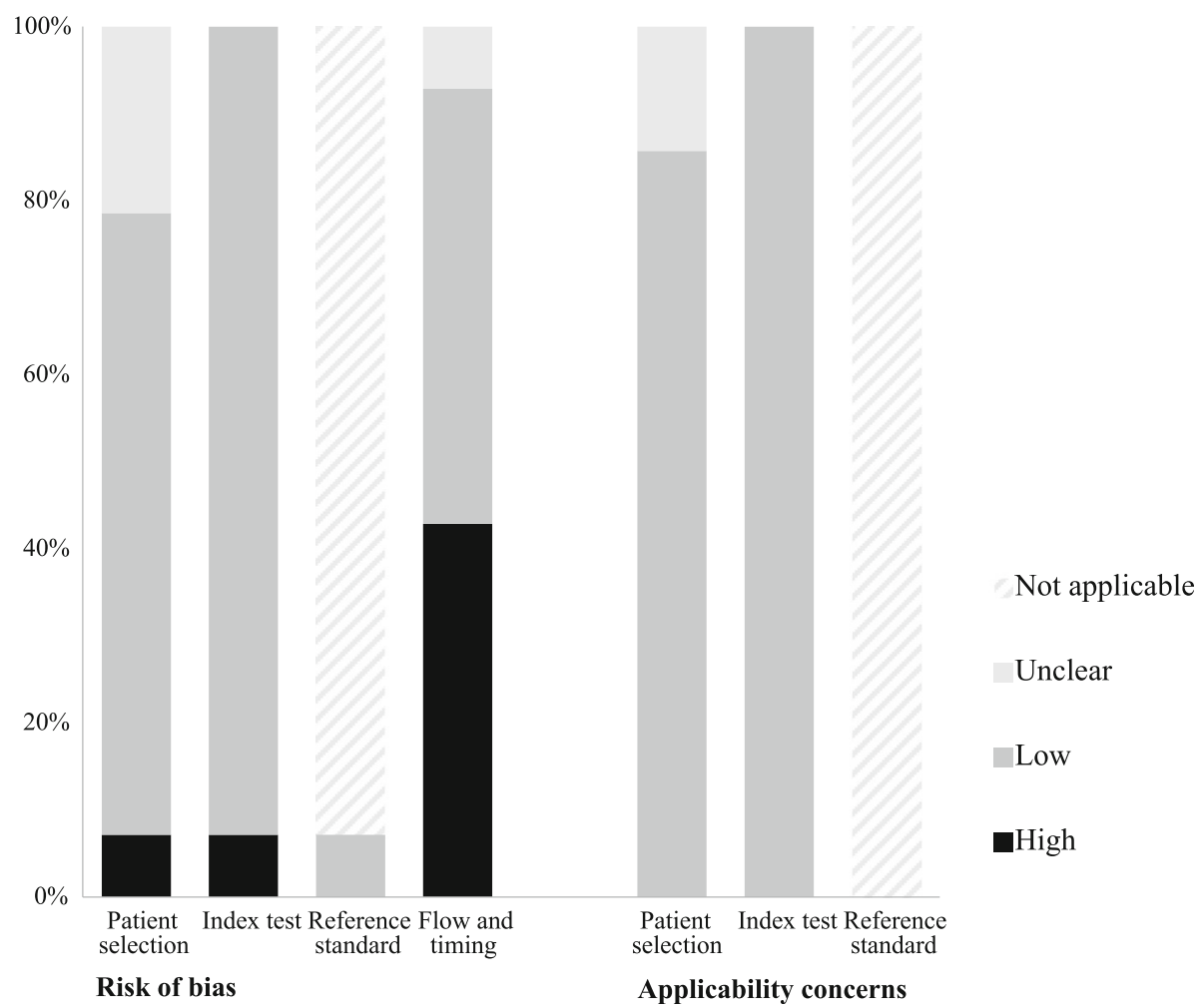

Fig. 3 Quality assessment of the studies

children $<12$ years, but was above the highest fifth centile values for children > 12 years. The cut-off from Paediatric Advanced Life Support (PALS) agreed well for children $<12$ years but was below the fifth centile values for children $>12$ years. The cut-off of Parshuram's early warning score (PEWS) agreed well for children $>12$ years [34]. Three other cut-offs were mostly below the fifth centiles (Goldstein, primary paediatric care and Paediatric Risk of Mortality III (PRISM III)) [30, 31, 35], and one cut-off had higher values (Nelson) [36].

\section{Discussion}

This systematic review demonstrates large variation among commonly used paediatric reference values for systolic hypotension. In general, the clinical guidelines are not based on available evidence and showed variable agreement with existing population-based blood pressure centiles. The reviewed literature addressing populationbased centiles showed limited studies in children $<1$ year of age.

Reference ranges of blood pressure are influenced by multiple factors such as age, gender, height, ethnicity and method of measurement [22]. In the literature, low centiles for blood pressure are often presented for different ages and in some cases for height. To facilitate interpretation, guidelines provide simplified cut-off values for hypotension for various age groups. For early recognition of acutely ill children, these simplified reference values are essential for clinicians.

The evidence for clinically used cut-offs for hypotension is mostly unclear as only five clinical cut-offs for hypotension reported accurate literature references. Our systematic search shows availability of population-based centiles that could provide evidence for lower reference values of blood pressure. Although not evidence based, we propose that clinical cut-offs for hypotension should not exceed the fifth centile. Clinical cut-offs that are generally below the fifth centile may possibly be too low, whilst clinical cut-offs that are generally above the fifth centile may be too high. These high clinical cut-offs may classify too many patients incorrectly as hypotensive since by definition $5 \%$ of healthy children will fall below this centile. In children $<12$ years, the values of PALS have good agreement with the low centiles, but for children age $>12$ years, the PALS could possibly be too low.

Our results are in line with a previous study that compared three clinical cut-offs with the fifth centile, based on a mathematical analysis of a large sample of healthy children [4]. They reported that the fifth centile for systolic blood pressure was generally below three clinical 
cut-offs for hypotension. Sarganas et al. found that low centiles from a German and US population were higher than the PALS definition in children $>13$ years [23]. In contrast to the previous studies, our study conducted an exhaustive systematic search for population-based centiles in all ages and compared them with a large sample of cut-offs for hypotension that are widely used in clinical practice. Our study identified only two studies that provided blood pressure centiles in children $<1$ year including one study in new-borns and one at age of 6 months $[17,24]$. Therefore, more studies providing reference values of blood pressure in children $<1$ year are required.

Reference values based on healthy children may not be accurate for acutely ill children, as pain and distress could increase blood pressure values. In addition, cuff size, movement of limbs, crying and uncooperativeness influence the measured values. In the interpretation of the measured values, these factors should be accounted for.

There is no consensus on which definition of hypotension should be used for the assessment of acutely ill children. Hypotension defined by APLS, PALS and PEWS showed an association with serious illness, adjusted for tachycardia. These definitions, however, lacked sensitivity for serious illness [3]. In our systematic review, the PALS cut-off showed the best agreement with the values based on healthy children with an average of $4 \mathrm{mmHg}$ difference from the weighted median of the population-based fifth centiles. In addition, current guidelines do not agree on treatment targets for blood pressure after identification of hypotension in critically ill children. The goal for treatment target of blood pressure is to maintain adequate tissue perfusion. The guideline of International Liaison Committee on Resuscitation recommends targeting systolic blood pressure values higher than the fifth percentile for children who are postcardiac arrest [37], whilst the APLS and the surviving sepsis campaign [1] advise to maintain normal blood pressure for age without defining specific measures. The American College of Critical Care Medicine recommends to use the 50th centile of the mean arterial pressure (MAP) and to use perfusion pressure (MAPcentral venous pressure) to guide treatment [27]. Some evidence is available suggesting higher MAP levels are needed to improve outcome in traumatic brain injury and central nervous system infections in children [2, 38]. Trials in adult critically ill patients with septic shock showed that targeting higher mean arterial pressure levels of $75-85 \mathrm{mmHg}$ did not influence mortality or other adverse events [39, 40]. Future trials will need to evaluate different blood pressure measures and targets in acutely ill children and relate those to interventions and relevant clinical outcomes.

Our review focused on systolic blood pressure and did not include mean arterial blood pressure or diastolic blood pressure. Although the mean arterial pressure is often used in critical care, we focused on systolic hypotension for general illness, since in general, clinical guidelines only report hypotension definitions of systolic blood pressure.

\section{Strengths and limitations}

Major strengths of this study are the use of an extensive search strategy, the overview of low reference values of blood pressure in healthy children covering all ages and the comparison with a diverse sample of clinical cut-offs of hypotension that are widely used in practice. Although we used a sensitive search strategy in multiple databases, it is possible we have not included all available data. Since we focused on lower age-related centiles, we excluded studies that reported blood pressure centiles solely for height or body mass index.

This study has some limitations. First, the selected sample of clinical definitions was not exhaustive and various blood pressure cut-offs in early warning scores and mortality score were not included. We selected Parshuram's early warning score and the PRISM III mortality score as these have been validated and are commonly used in practice. We acknowledge that these cut-offs are part of a score containing other clinical markers. In addition, the PRISM III score has been developed specifically for predicting mortality in critically ill children.

Second, blood pressure is determined by height and we only included blood pressure values for the median height value. However, height is usually not available in the assessment of acutely ill children and none of the clinical guidelines accounted for height. Third, we focused on non-invasive measurement methods including oscillometric and auscultatory measurements. Oscillometric measured values could be different than auscultatory measurements [41]. As different devices were used in the studies and their validity in the assessment of low blood pressure is unknown, we combined centiles for oscillometric and auscultatory measurements. Fourth, since non-invasive blood pressure measurements could overestimate hypotension when compared to invasive arterial measurement, generalization of our study to invasive measurements should be undertaken with caution [42-44].

\section{Conclusion}

Large variation exists among paediatric cut-offs for hypotension. In general, these clinical definitions are not evidence-based and have variable agreement with existing population-based blood pressure lower centiles. 
For children $<12$ years, the PALS definition agreed well. For children $>12$ years, the PEWS agreed well but the PALS cut-off possibly underestimates and the APLS overestimates hypotension. Future studies should focus on developing reference values for hypotension for acutely ill children.

\section{Supplementary information}

Supplementary information accompanies this paper at https://doi.org/10. 1186/s13054-019-2653-9.

Additional file 1. Systematic search strategy.

Additional file 2. Clinical definitions for hypotension and range of 5 th centile of systolic blood pressure for girls according to age.

Additional file 3. 5th centile of systolic blood pressure and median (IQR) for boys.

Additional file 4. 5th centile of systolic blood pressure and median (IQR) for girls.

Additional file 5. Clinical cut-offs for hypotension.

\section{Abbreviations}

APLS: Advanced Paediatric Life Support; MAP: Mean arterial pressure; PALS: Paediatric Advanced Life Support; PEWS: Parshuram's early warning score; PRISM: Paediatric Risk of Mortality

\section{Acknowledgements}

We would like to thank Wichor M. Bramer, Medical Library Erasmus MC, for the development of the search strategy.

\section{Authors' contributions}

All authors substantially contributed to the conception and design of the study and interpretation of the findings. $\mathrm{NH}$ and JZ performed the study selection and risk of bias assessment. NH extracted the data, performed the analysis and wrote the first draft of the manuscript. All authors revised the manuscript for important intellectual content and gave their approval of the final version.

\section{Funding}

N. Hagedoorn has received funding from the European Union's Horizon 2020 research and innovation programme under Grant Agreement No. 668303.

\section{Availability of data and materials}

The datasets used and/or analysed during the current study are available from the corresponding author on reasonable request.

Ethics approval and consent to participate

Not applicable

\section{Consent for publication}

Not applicable

\section{Competing interests}

The authors declare that they have no competing interests.

Received: 1 August 2019 Accepted: 21 October 2019

Published online: 27 November 2019

\section{References}

1. Dellinger RP, Levy MM, Rhodes A, Annane D, Gerlach H, Opal SM, Sevransky JE, Sprung CL, Douglas IS, Jaeschke R, et al. Surviving sepsis campaign: international guidelines for management of severe sepsis and septic shock: 2012. Crit Care Med. 2013:41(2):580-637.

2. Suttipongkaset $P$, Chaikittisilpa N, Vavilala MS, Lele AV, Watanitanon A, Chandee T, Krishnamoorthy $\mathrm{V}$. Blood pressure thresholds and mortality in pediatric traumatic brain injury. Pediatrics. 2018;142(2).
3. Hagedoorn NN, Zachariasse JM, Moll HA. Association between hypotension and serious illness in the emergency department: an observational study. Arch Dis Child. 2019. https://doi.org/10.1136/archdischild-2018-316231.

4. Haque IU, Zaritsky AL. Analysis of the evidence for the lower limit of systolic and mean arterial pressure in children. Pediatr Crit Care Med. 2007;8(2):138-44.

5. Marlais M, Lyttle MD, Inwald D. Ten concerns about blood pressure measurement and targets in paediatric sepsis. Intensive Care Med. 2017; 43(3):433-5.

6. Advanced Life Support Group. Advanced paediatric life support: the practical approach. 5th ed. London: BMJ publishing group; 2011.

7. Kleinman ME, Chameides L, Schexnayder SM, Samson RA, Hazinski MF, Atkins DL, Berg MD, de Caen AR, Fink EL, Freid EB, et al. Pediatric Advanced Life Support: 2010 American Heart Association guidelines for cardiopulmonary resuscitation and emergency cardiovascular care. Pediatrics. 2010;126(5):e1361-99.

8. Goldstein B, Giroir B, Randolph A, International Consensus Conference on Pediatric S. International pediatric sepsis consensus conference: definitions for sepsis and organ dysfunction in pediatrics. Pediatr Crit Care Med. 2005; 6(1):2-8.

9. World Bank Country and Lending Groups. http://data.worldbank.org/about/ country-and-lending-groups\#tower_middle_income. Accessed 27 July 2015.

10. Sanderson S, Tatt ID, Higgins JP. Tools for assessing quality and susceptibility to bias in observational studies in epidemiology: a systematic review and annotated bibliography. Int J Epidemiol. 2007;36(3):666-76.

11. Whiting PF, Rutjes AW, Westwood ME, Mallett S, Deeks JJ, Reitsma JB, Leeflang MM, Sterne JA, Bossuyt PM, Group Q. QUADAS-2: a revised tool for the quality assessment of diagnostic accuracy studies. Ann Intern Med. 2011;155(8):529-36.

12. Antal M, Regoly-Merei A, Nagy K, Greiner E, Biro L, Domonkos A, Balajti A, Szorad I, Szabo C, Mozsary E. Representative study for the evaluation of ageand gender-specific anthropometric parameters and blood pressure in an adolescent Hungarian population. Ann Nutr Metab. 2004:48(5):307-13.

13. Barba G, Buck C, Bammann K, Hadjigeorgiou C, Hebestreit A, Marild S, Molnar D, Russo P, Veidebaum T, Vyncke $K$, et al. Blood pressure reference values for European non-overweight school children: the IDEFICS study. Int J Obes. 2014:38:S48-56.

14. Blake KV, Gurrin LC, Evans SF, Newnham JP, Landau LI, Stanley FJ, Beilin LJ. Reference ranges for blood pressure in preschool Australians, obtained by oscillometry. J Paediatr Child Health. 2000;36(1):41-6.

15. Grajda A, Kulaga Z, Gurzkowska B, Wojtylo M, Gozdz M, Litwin M. Preschool children blood pressure percentiles by age and height. J Hum Hypertens. 2017:31(6):400-8.

16. Hediger ML, Schall Jl, Katz SH. Resting blood pressure and pulse rate distributions in black adolescents: the Philadelphia Blood Pressure Project. Pediatrics. 1984;74(6):1016-21.

17. Kent AL, Kecskes Z, Shadbolt B, Falk MC. Blood pressure in the first year of life in healthy infants born at term. Pediatr Nephrol. 2007:22(10):1743-9.

18. Karmar RT, Holtback U, Anita Bergh A, Svensson E, Wuhl E. Oscillometric casual blood pressure normative standards for Swedish children using ABPM to exclude casual hypertension. Am J Hypertens. 2014;28(4):459-68.

19. Krzyzaniak A, Krzywinska-Wiewiorowska M, Stawinska-Witoszynska B, Kaczmarek M, Krzych L, Kowalska M, Szilagyi-Pagowska I, Palczewska I, Karch A, Josko J, et al. Blood pressure references for Polish children and adolescents. Eur J Pediatr. 2009;168(11):1335-42.

20. Lurbe E, Redon J, Liao YL, Tacons J, Cooper RS, Alvarez V. Ambulatory blood-pressure monitoring in normotensive children. J Hypertens. 1994; 12(12):1417-23.

21. Rosner B, Cook N, Portman R, Daniels S, Falkner B. Determination of blood pressure percentiles in normal-weight children: some methodological issues. Am J Epidemiol. 2008;167(6):653-66.

22. National High Blood Pressure Education Program Working Group on High Blood Pressure in children and adolescents. The fourth report on the diagnosis, evaluation, and treatment of high blood pressure in children and adolescents. Pediatrics. 2004;114(2 Suppl 4th Report):555-76.

23. Sarganas G, Schaffrath Rosario A, Berger S, Neuhauser HK. An unambiguous definition of pediatric hypotension is still lacking: gaps between two percentile-based definitions and PALS / ATLS guidelines. J Trauma Acute Care Surg. 2018

24. Satoh M, Inoue R, Tada H, Hosaka M, Metoki H, Asayama K, Murakami T, Mano N, Ohkubo T, Yagihashi $K$, et al. Reference values and associated factors for Japanese newborns' blood pressure and pulse rate: the babies' 
and their parents' longitudinal observation in Suzuki Memorial Hospital on intrauterine period (BOSHI) study. J Hypertens. 2016;34(8):1578-85.

25. Schwandt P, Scholze JE, Bertsch T, Liepold E, Haas GM. Blood pressure percentiles in 22,051 German children and adolescents: the PEP Family Heart Study. Am J Hypertens. 2015;28(5):672-9.

26. Weiss NS, Hamill PV, Drizd T. Blood pressure levels of children 6-11 years: relationship to age, sex, race, and socioeconomic status, United States. Vital Health Stat [11]. 1973;(135):1-30.

27. Davis AL, Carcillo JA, Aneja RK, Deymann AJ, Lin JC, Nguyen TC, OkhuysenCawley RS, Relvas MS, Rozenfeld RA, Skippen PW, et al. American College of Critical Care Medicine clinical practice parameters for hemodynamic support of pediatric and neonatal septic shock. Crit Care Med. 2017;45(6):1061-93.

28. Barry P, Morris K, Ali T. Paediatric intensive care: OUP Oxford; 2010.

29. Rogers MC. Textbook of pediatric intensive care: Williams \& Wilkin; 1992.

30. Goldstein B, Giroir B, Randolph A. Reply: values for systolic blood pressure. Pediatr Crit Care Med. 2005;6(4):500-1.

31. Hoekelman RA. Primary pediatric care: Mosby; 1997.

32. Barkin RM. Pediatric emergency medicine. 2nd ed: Mosby; 1996.

33. Nadas A. Pediatric cardiology. 3rd ed: WB Saunders Co; 1976.

34. Parshuram CS, Duncan HP, Joffe AR, Farrell CA, Lacroix JR, Middaugh KL, Hutchison JS, Wensley D, Blanchard N, Beyene J, et al. Multicentre validation of the bedside paediatric early warning system score: a severity of illness score to detect evolving critical illness in hospitalised children. Crit Care. 2011;15(4):R184.

35. Pollack MM, Patel KM, Ruttimann UE. PRISM III: an updated Pediatric Risk of Mortality score. Crit Care Med. 1996;24(5):743-52.

36. Behrman RE, Kliegman R, Jenson HB. Nelson textbook of pediatrics: Saunder; 2004.

37. de Caen AR, Berg MD, Chameides L, Gooden CK, Hickey RW, Scott HF, Sutton RM, Tijssen JA, Topjian A, van der Jagt EW, et al. Part 12: Pediatric Advanced Life Support: 2015 American Heart Association guidelines update for cardiopulmonary resuscitation and emergency cardiovascular care. Circulation. 2015;132(18 Suppl 2):S526-42.

38. Spaite DW, Hu C, Bobrow BJ, Chikani V, Barnhart B, Gaither JB, Denninghoff KR, Adelson PD, Keim SM, Viscusi C, et al. Association of out-of-hospital hypotension depth and duration with traumatic brain injury mortality. Ann Emerg Med. 2017.

39. Asfar P, Meziani F, Hamel JF, Grelon F, Megarbane B, Anguel N, Mira JP, Dequin PF, Gergaud S, Weiss N, et al. High versus low blood-pressure target in patients with septic shock. N Engl J Med. 2014;370(17):1583-93.

40. Lamontagne F, Day AG, Meade MO, Cook DJ, Guyatt GH, Hylands M, Radermacher P, Chretien JM, Beaudoin N, Hebert P, et al. Pooled analysis of higher versus lower blood pressure targets for vasopressor therapy septic and vasodilatory shock. Intensive Care Med. 2018;44(1):12-21.

41. Park MK, Menard SW, Yuan C. Comparison of auscultatory and oscillometric blood pressures. Arch Pediatr Adolesc Med. 2001;155(1):50-3.

42. Joffe R, Duff J, Garcia Guerra G, Pugh J, Joffe AR. The accuracy of blood pressure measured by arterial line and non-invasive cuff in critically ill children. Crit Care. 2016;20(1):177.

43. Ray S, Rogers L, Noren DP, Dhar R, Nadel S, Peters MJ, Inwald DP. Risk of over-diagnosis of hypotension in children: a comparative analysis of over 50,000 blood pressure measurements. Intensive Care Med. 2017;43(10): $1540-1$.

44. Holt TR, Withington DE, Mitchell E. Which pressure to believe? A comparison of direct arterial with indirect blood pressure measurement techniques in the pediatric intensive care unit. Pediatr Crit Care Med. 2011 12(6):e391-4.

\section{Publisher's Note}

Springer Nature remains neutral with regard to jurisdictional claims in published maps and institutional affiliations.

Ready to submit your research? Choose BMC and benefit from:

- fast, convenient online submission

- thorough peer review by experienced researchers in your field

- rapid publication on acceptance

- support for research data, including large and complex data types

- gold Open Access which fosters wider collaboration and increased citations

- maximum visibility for your research: over $100 \mathrm{M}$ website views per year

At BMC, research is always in progress.

Learn more biomedcentral.com/submissions 